\title{
Intravesical dexmedetomidine instillation reduces postoperative catheter-related bladder discomfort in male patients under general anesthesia: a randomized controlled study
}

\author{
Hong Chen ${ }^{\dagger}$, Bin Wang ${ }^{\dagger}$, Qin Li, Juan Zhou, Rui Li and Ye Zhang ${ }^{*}$ (i)
}

\begin{abstract}
Background: The catheter-related bladder discomfort (CRBD) of male patients is a common clinical problem, albeit lacking effective solutions. The present study aimed to investigate whether intravesical dexmedetomidine instillation alleviates the postoperative urinary discomfort in male patients with catheter under general anesthesia.

Methods: This single-blinded, prospective, randomized study included a total of 167 male patients American Society of Anesthesiologists (ASA) physical status I-II scheduled for surgery under general anesthesia were allocated to two groups: 84 in the dexmedetomidine group and 83 in the control group. Dexmedetomidine group patients received intravesical instillation of the drug $0.5 \mu \mathrm{g} / \mathrm{kg}$ and normal saline $20 \mathrm{~mL}$, while the control group received intravesical instillation of $20 \mathrm{~mL}$ normal saline. The catheter was clamped for $30 \mathrm{~min}$ after intravesical instillation for all patients. CRBD scores and urethra pain numerical rating scale (NRS) scores were measured at admittance to post-anesthesia care unit (PACU) (T0), intravesical instillation (T1), $30 \mathrm{~min}$ (T2), $60 \mathrm{~min}$ (T3), $2 \mathrm{~h}$ (T4) after intravesical instillation, discharged from PACU (T5), and $6 \mathrm{~h}$ (T6) and $24 \mathrm{~h}$ (T7) after the operation. Patient satisfaction at discharge from PACU and $24 \mathrm{~h}$ post-operation were compared between the two groups.
\end{abstract}

Results: CRBD scores and urethra pain NRS scores after 30 min of intravesical dexmedetomidine instillation to $24 \mathrm{~h}$ post-operation were significantly lower than the control group $(p<0.001)$, and patient satisfaction was higher at discharge from PACU and $24 \mathrm{~h}$ post-operation $(p<0.001)$. No differences were detected in Steward score out of PACU $(p=0.213)$ and from the time of the end of operation to fully awake $(p=0.417)$.

Conclusion: Intravesical dexmedetomidine instillation reduces postoperative urinary discomfort and urethra pain and improves satisfaction in male patients under general anesthesia.

Trial registration: Chinese Clinical Trial Registry (No. ChiCTR1800016429), date of registration 1st June 2018. Keywords: Dexmedetomidine, Intravesical instillation, Catheter-related bladder discomfort, General anesthesia

\footnotetext{
* Correspondence: zhangye_hassan@sina.com

${ }^{\dagger}$ Hong Chen and Bin Wang contributed equally to this work.

Department of Anesthesiology and Perioperative Medicine, The Second Affiliated Hospital of Anhui Medical University, 678\# Furong Road, Hefei, Anhui Province, China
}

C C The Author(s). 2020 Open Access This article is licensed under a Creative Commons Attribution 4.0 International License, which permits use, sharing, adaptation, distribution and reproduction in any medium or format, as long as you give appropriate credit to the original author(s) and the source, provide a link to the Creative Commons licence, and indicate if changes were made. The images or other third party material in this article are included in the article's Creative Commons licence, unless indicated otherwise in a credit line to the material. If material is not included in the article's Creative Commons licence and your intended use is not permitted by statutory regulation or exceeds the permitted use, you will need to obtain permission directly from the copyright holder. To view a copy of this licence, visit http://creativecommons.org/licenses/by/4.0/ The Creative Commons Public Domain Dedication waiver (http://creativecommons.org/publicdomain/zero/1.0/) applies to the data made available in this article, unless otherwise stated in a credit line to the data. 


\section{Background}

Catheter-related bladder discomfort (CRBD) after the operation is a common adverse reaction; however, many surgery patients need an indwelling catheter during or after the operation. The incidence of CRBD is $47-90 \%$ $[1,2]$, and catheter maladjustment is common, especially in male patients $[3,4]$. Reportedly, $27-55 \%$ of the patients experience moderate or severe catheter-related bladder discomfort symptoms in the post-anesthesia care unit (PACU) $[3,5]$. CRBD leads to restlessness, delirium, decreased satisfaction, and a rise in postoperative complications, such as incision rupture, bleeding, hemodynamic instability, the severity of coronary heart disease [1]. Thus, how to relieve postoperative CRBD, reduce the incidence of related complications, improve patient satisfaction, and shorten the time of anesthesia recovery observation has become needs to be resolved urgently in clinical practice [6-9].

Dexmedetomidine is a type of high selective adrenergic $\alpha-2$ receptor agonist, which has the effects of sedation, analgesia, and anti-anxiety. Several studies have confirmed that dexmedetomidine can reduce the incidence of postoperative agitation and delirium [10-14]. Moreover, dexmedetomidine might reduce bladder contractility via $\alpha-2$ receptor agonism, M3 muscarinic receptor antagonism [15-17], and the incidence and severity of catheter-related bladder discomfort after general anesthesia [16, 18-21]. These studies were based on the intravenous administration of dexmedetomidine, which increases the risk of arrhythmia [22].

A large number of studies [23-25] showed that intravesical instillation is an effective way of drug administration, which exerts an obvious effect on the treatment of bladder-related diseases. Concurrently, the intravesical instillation of drugs can reduce the systemic response. However, whether dexmedetomidine can be used by intravesical instillation to reduce CRBD and improve the tolerance to indwelling catheter has not yet been reported. Thus, the present study aimed to investigate whether intravesical dexmedetomidine instillation can alleviate the postoperative urinary discomfort in male patients with general anesthesia.

\section{Methods}

\section{Study design}

This single-center, single-blinded, prospective, randomized study was approved by the Institutional Review Board and Hospital Research Ethics Committee of the Second Affiliated Hospital of Anhui Medical University [No. PJ-YX2018-004 (F2)]. The protocol of the study was registered in the Chinese Clinical Trial Registry (No. ChiCTR1800016429) and executed in accordance with the CONSORT checklist. Each patient provided written informed consent before participation in the study.
Patients can withdraw from the study at any time according to their wishes. All patients were enrolled between June 2018 and April 2019. The inclusion criteria were as follows: male patients aged 18-70 years and American Society of Anesthesiologists (ASA) physical status I-II undergoing elective surgery, scheduled general anesthesia, and intraoperative catheter insertion. The exclusion criteria were as follows: urology patients, endstage renal disease, pathological obesity, central nervous system dysfunction, chronic pain, cerebral infarction, mental disorder of consciousness, change in surgical and anesthesia plans, without CRBD when admitted to PACU. In this single-blinded study, patients were blinded to the group allocation. However, it was not blinded to anesthesiologists, PACU nurses, surgeons and ward nurses because this information is important for perioperative management of patients.

\section{Sample size}

PASS 11.0 software was used to compare the mean of two independent samples. According to the preexperiment CRBD score, the mean value of the control group was 2.25, and the standard deviation was 0.66 . The mean value of the dexmedetomidine group was 1.9 and the standard deviation was 0.67 . Set $\alpha$ as $0.05, \beta$ as 0.9 , using bilateral test, the sample size of each group is 75 . Increase the sample size $20 \%$ to prevent the sample drop-out, so we chose 90 patients in each group.

\section{Patient randomization}

Male patients with CRBD into PACU were randomly divided into two groups with an allocation ratio of 1:1 according to the computerized randomization table in a blinded manner. Random numbers to each patient while the nurses collected postoperative data from the patients.

\section{Anesthesia application}

The surgery and anesthesia program of the patient was similar to that of the other patients. Electrocardiography (ECG), peripheral oxygen saturation $\left(\mathrm{SpO}_{2}\right)$, noninvasive blood pressure (NBP), and respiratory rate (RR) were monitored routinely after the patients were admitted to the operating room. The vein channel was established with a 22-gauge indwelling needle. Oxygen was inhaled by mask (oxygen flow rate was $4-5 \mathrm{~L} / \mathrm{min}$ ). Midazolam $0.025 \mathrm{mg} / \mathrm{kg}$, sufentanil $2-4 \mu \mathrm{g} / \mathrm{kg}$, etomidate $1-2 \mathrm{mg} / \mathrm{kg}$, and rocuronium $0.9 \mathrm{mg} / \mathrm{kg}$ were injected intravenously for anesthesia induction. After intubation, a ureteral catheter was used for catheterization, followed by anesthesia maintenance propofol $2-4 \mathrm{mg} / \mathrm{kg} / \mathrm{h}$, remifentanil $10-20 \mu \mathrm{g} / \mathrm{kg} / \mathrm{h}$, and continued addition of cisatracurium to maintain muscle relaxation. At the end of the operation, the muscle relaxation and consciousness 
of the patient were restored, the tracheal tube was removed and sent to PACU for observation.

\section{Catheterization}

After induction of anesthesia, 16F latex ureteral catheter (Huaxing Medical Equipment Co., Ltd., China) was used for all participants. Catheterization was performed by surgeons with more than 5 years experience. The operation process must be as gentle as possible, and the whole process was sterile. Before catheterization, paraffin oil fully lubricated the catheter. After the successful placement of the catheter, $10 \mathrm{~mL}$ of normal saline was injected into the cuff balloon to prevent catheter slippage. After catheterization, the catheter was fixed on the inside of the thigh to prevent urinary tract injury caused by catheter pulling.

\section{Interventions}

As a safe and widely used drug, intravesical dexmedetomidine instillation method has been approved by the Institutional Review Board and Hospital Research Ethics Committee of the Second Affiliated Hospital of Anhui Medical University. In the dexmedetomidine group, $0.5 \mu \mathrm{g} / \mathrm{kg}$ dexmedetomidine was solubilized in $20 \mathrm{~mL}$ normal saline infused from the ureteral catheter to bladder for intravesical dexmedetomidine instillation. In the control group, $20 \mathrm{~mL}$ of normal saline was infused from the ureteral catheter to the bladder. After instillation, the ureteral catheter was clipped for $30 \mathrm{~min}$ and then unclipped.

\section{Assessments}

The primary outcome endpoint was CRBD score, and the second outcome endpoint was urethra pain NRS score and patient's satisfaction. The duration of anesthesia, the time length of operation, the time from the end of the operation to full consciousness, and patient characteristics were recorded. Mean arterial pressure (MAP), heart rate (HR), $\mathrm{RR}, \mathrm{SpO}_{2}, \mathrm{CRBD}$ score, and urethra pain NRS score were recorded when the patient was sent to PACU (T0), the time of intravesical instillation with dexmedetomidine or normal saline (T1), 30 min after intravesical instillation (T2), $1 \mathrm{~h}$ after intravesical instillation (T3), $2 \mathrm{~h}$ after intravesical instillation (T4), the time point of leaving PACU (T5), $6 \mathrm{~h}$ after operation (T6), and $24 \mathrm{~h}$ after opertaion (T7). The NRS score of urethra pain and the complications after intravesical instillation were also recorded. The patient satisfaction score were recorded when leaving PACU and 24 $h$ after the operation. The NRS score was used for the assessment of urethra pain in both groups. CRBD score: 0 point, patients have no discomfort at all; 1 point, patients have slight discomfort, only when asked to show discomfort; 2 points, patients have moderate discomfort, frequency of urination, the urgency of urination, feeling of lower abdominal distension, which is not easy to bear; 3 points, the patient had severe discomfort, intolerable distension, urethral pain, frequent urination with strong restlessness, and needed to be removed. Ramsay score: 1 point, the patient is restless and fidgety; 2 points, the patient is quiet and cooperative; 3 points, the patient is sleepy and can follow the instructions; 4 points, the patient is in a sleep state and can wake up; 5 points, the respiratory response of the patient is slow; 6 points, the patient is deep asleep and has no response to stimulation. Patient satisfaction score is consisting of integers from 1 point to 5 points: 1 point means dissatisfied and 5 points mean very satisfied. The urethra pain NRS scores consists of integers from 0 to 10 points; 0 point means no urethra pain, and 10 points indicate intense urethra pain. Subsequently, the patients selected an integer to describe the intensity of their urethra pain while using a ureteral catheter.

\section{Statistical analysis}

SPSS software (version 22.0, Chicago, USA) was used for statistical analysis. The age, weight, blood, and other measurement data of patients were presented as mean \pm standard deviation. The ASA classification data were expressed as counts. Student's $t$-test or the MannWhitney $U$ test was used for continuous variables, such as age and weight. The $\chi^{2}$ or Fisher's exact tests were assessed for categorical variables, such as ASA grade and patient satisfaction score. ANOVA was used for the comparison of MAP, $\mathrm{HR}, \mathrm{SpO}_{2}$, and other data at different time points. $p$-value $<0.05$ was accepted as statistically significant.

\section{Results}

\section{Study demographics}

A total of 289 male patients were screened in this study, of which, 109 cases were excluded; among them, 96 did not present CRBD, 6 were not meeting the other inculsion criteria, 5 refused to participate in the study, and 2 were excluded for other reasons. A total of 180 male patients with CRBD were randomly and equally divided into both groups when into PACU. Six cases in the dexmedetomidine group and 7 cases in the control group did not complete the experiment because transfer to intensive care unit ( 2 cases), delirium (10 cases), or catheter falls off ( 1 cases). None of the patients were lost follow-up. Finally, 84 patients in the dexmedetomidine group and 83 patients in the control group were included in the analysis (Fig. 1). The incidence of CRBD was $65.2 \%$.

No significant difference was detected between the two groups in age, weight, ASA grade, duration of operation, duration of anesthesia, Steward's score when 


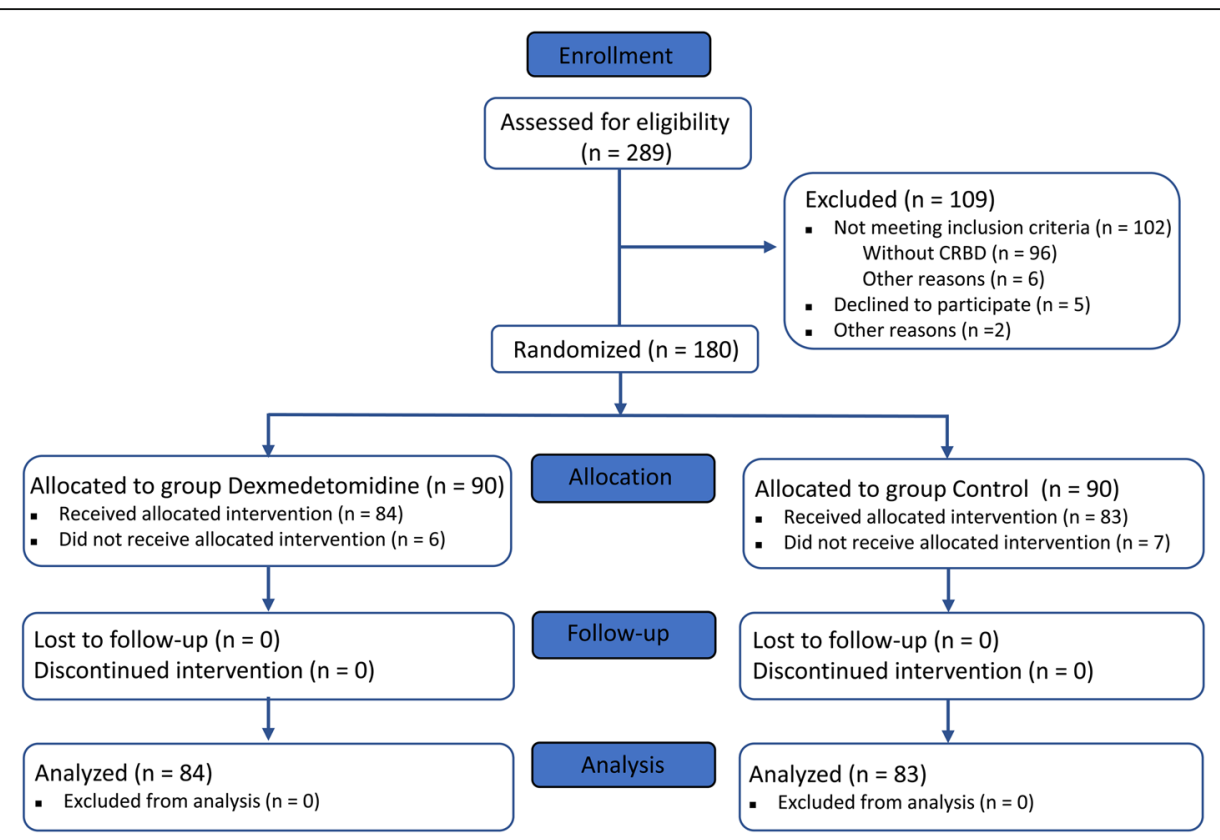

Fig. 1 Schematic of the study with a CONSORT diagram. CRBD, catheter-related bladder discomfort

leaving PACU, the time length of operation end to fully awake, catheter removal time (Table 1) and type of operation. There was no significant difference was observed in $\mathrm{HR}, \mathrm{RR}, \mathrm{MAP}$, and $\mathrm{SpO}_{2}$ in the two groups from T0 to T7 (Table 2), as well as no complications, occurred in either of the groups. Systematic pain NRS score decreased at $\mathrm{T} 4$.

\section{CRBD and urethra pain NRS scores}

Compared to the control group, the CRBD in the dexmedetomidine group was significantly improved at T3, T4, T5, T6, and T7 $(p<0.001)$ (Fig. 2a), while the urethra pain NRS scores of patients was significantly decreased $(p<0.001)$ (Fig. 2b).

\section{Patient's satisfaction}

Compared to the control group, the patient's satisfaction in the dexmedetomidine group in PACU (Fig. 3a) and $24 \mathrm{~h}$ post-operation (Fig. 3b) increased significantly $(p<0.001)$.

\section{Discussion}

In the present study, we observed that $0.5 \mu \mathrm{g} / \mathrm{kg}$ dexmedetomidine intravesical instillation can significantly

Table 1 Descriptive variables of the control group and dexmedetomidine group

\begin{tabular}{|c|c|c|c|}
\hline & $\begin{array}{l}\text { Control } \\
(n=83)\end{array}$ & $\begin{array}{l}\text { Dexmedetomidine } \\
(n=84)\end{array}$ & $p$-value \\
\hline Age (year) & $51.2 \pm 13.2$ & $54.7 \pm 12.5$ & 0.076 \\
\hline Weight (kg) & $68.1 \pm 10.5$ & $68.3 \pm 11.1$ & 0.919 \\
\hline ASA grade $(I / I I)$ & $7 / 76$ & $9 / 75$ & 0.617 \\
\hline Time length of operation (min) & $146.6 \pm 70.8$ & $160.2 \pm 62.7$ & 0.193 \\
\hline Time length of anesthesia (min) & $175.2 \pm 72.2$ & $190.2 \pm 67.6$ & 0.122 \\
\hline Steward score out of PACU & $5.98 \pm 0.15$ & $5.95 \pm 0.21$ & 0.213 \\
\hline Time length of operation end to fully awake (min) & $13.6 \pm 6.5$ & $14.9 \pm 7.3$ & 0.417 \\
\hline Ureteral catheter removal time (6-12 h/12-24 h/more than $24 \mathrm{~h}$ after operation) & $12 / 46 / 25$ & 9/38/37 & 0.173 \\
\hline $\begin{array}{l}\text { Operation type (general surgery/thoracic surgery/orthopedics/otolaryngology/stomatology/ plastic } \\
\text { surgery) }\end{array}$ & $\begin{array}{l}33 / 14 / 31 / 5 / 0 / \\
0\end{array}$ & $31 / 20 / 23 / 7 / 1 / 2$ & 0.343 \\
\hline The number of patients receiving postoperative analgesia treatment & $22(26.5 \%)$ & $21(25.0 \%)$ & 0.482 \\
\hline
\end{tabular}

Values are presented as mean (standard deviation) or counts ASA American society of anesthesiologists 
Table 2 Patients vital signs of group Dexmedetomidine $(n=84)$ and group Control $(n=83)$ at different time points

\begin{tabular}{|c|c|c|c|c|c|c|c|c|c|}
\hline & Group & TO & T1 & T2 & T3 & T4 & T5 & T6 & T7 \\
\hline \multirow[t]{2}{*}{$\mathrm{HR}$} & Control & $76.6 \pm 15.4$ & $75.9 \pm 15.0$ & $77.4 \pm 14.7$ & $79.0 \pm 14.0^{\# \#}$ & $80.1 \pm 14.3^{\# \#}$ & $80.9 \pm 14.2^{\text {\#\# }}$ & $80.2 \pm 12.4^{\# \#}$ & $79.7 \pm 12.5^{\#}$ \\
\hline & Dexmedetomidine & $75.6 \pm 15.2$ & $75.4 \pm 15.1$ & $75.8 \pm 14.5$ & $77.8 \pm 13.9^{\#}$ & $79.1 \pm 14.3^{\# \#}$ & $79.1 \pm 14.1^{\#}$ & $78.7 \pm 11.0^{\#}$ & $79.7 \pm 12.5$ \\
\hline \multirow[t]{2}{*}{ RR } & Control & $18.8 \pm 1.1$ & $18.8 \pm 1.1$ & $18.9 \pm 1.3$ & $19.2 \pm 1.0^{\# \#}$ & $19.1 \pm 1.0$ & $19.1 \pm 0.9^{\#}$ & $19.1 \pm 0.9^{\#}$ & $18.9 \pm 0.9$ \\
\hline & Dexmedetomidine & $18.8 \pm 1.5$ & $18.7 \pm 1.2$ & $18.5 \pm 1.2$ & $18.5 \pm 1.4$ & $18.7 \pm 1.1$ & $19.0 \pm 1.0$ & $18.7 \pm 0.8$ & $18.8 \pm 0.8$ \\
\hline \multirow[t]{2}{*}{ MAP } & Control & $98.9 \pm 16.1$ & $97.9 \pm 14.4$ & $97.8 \pm 14.5$ & $97.3 \pm 14.4$ & $95.6 \pm 14.4^{\#}$ & $94.3 \pm 12.7^{\# \#}$ & $91.4 \pm 11.5^{\# \#}$ & $89.6 \pm 10.5^{\# \#}$ \\
\hline & Dexmedetomidine & $98.4 \pm 15.2$ & $97.7 \pm 15.5$ & $95.4 \pm 14.3^{\# \#}$ & $94.8 \pm 14.2^{\# \#}$ & $94.1 \pm 12.8^{\# \#}$ & $92.8 \pm 12.3^{\# \#}$ & $91.5 \pm 10.6^{\# \#}$ & $89.6 \pm 8.6^{\# \#}$ \\
\hline \multirow[t]{2}{*}{$\mathrm{SPO}_{2}$} & Control & $98.7 \pm 1.1$ & $98.9 \pm 1.2$ & $98.6 \pm 1.3$ & $98.7 \pm 1.2$ & $98.7 \pm 1.1$ & $98.6 \pm 1.2$ & $98.3 \pm 1.0^{\# \#}$ & $98.3 \pm 0.7^{\# \#}$ \\
\hline & Dexmedetomidine & $98.7 \pm 1.8$ & $98.9 \pm 1.4$ & $98.8 \pm 1.4$ & $98.8 \pm 1.4$ & $98.8 \pm 1.1$ & $98.8 \pm 1.1$ & $98.4 \pm 0.9$ & $98.3 \pm 0.7$ \\
\hline \multirow{2}{*}{$\begin{array}{l}\text { Systemic pain } \\
\text { NRS score }\end{array}$} & Control & $3.2 \pm 1.2$ & $3.1 \pm 1.1$ & $2.5 \pm 0.7^{\# \#}$ & $2.4 \pm 0.7^{\# \#}$ & $2.3 \pm 0.7^{\# \#}$ & $2.2 \pm 0.7^{\# \#}$ & $2.3 \pm 1.0^{\# \#}$ & $1.4 \pm 0.9^{\# \#}$ \\
\hline & Dexmedetomidine & $3.0 \pm 1.1$ & $2.9 \pm 1.0$ & $2.5 \pm 0.8^{\# \#}$ & $2.2 \pm 0.7^{\# \#}$ & $2.1 \pm 0.6^{\# \#^{*}}$ & $2.0 \pm 0.6^{\# \#}$ & $2.2 \pm 1.4^{\# \#}$ & $1.3 \pm 0.8^{\# \#}$ \\
\hline
\end{tabular}

" $p$-value $<0.05$ compared to the same time of Group Control ( ${ }^{*} p$-value $\left.=0.021\right)$

\# $p$-value $<0.05$ compared to T0; ${ }^{\# \#} p$-value $<0.01$ compared to T0

Values are presented as mean \pm standard deviation

MAP Mean arterial pressure, $H R$ Heart rate, $R R$ Respiratory rate, $\mathrm{SpO}_{2}$ Pulse oximetry. Time course, the time point of the patient sent to PACU (T0), intravesical instillation (T1), 30 min after intravesical instillation (T2), $1 \mathrm{~h}$ after intravesical instillation (T3), $2 \mathrm{~h}$ after intravesical instillation (T4), leaving PACU (T5), $6 \mathrm{~h}$ after the operation (T6), $24 \mathrm{~h}$ after the operation (T7)

reduce the symptoms of postoperative catheter-related bladder discomfort and the urethral pain caused by catheter in male patients who received general anesthesia, and consequently, their satisfaction was improved. The improvement of these symptoms can sustain from $0.5-24 \mathrm{~h}$ after intravesical dexmedetomidine instillation.

CRBD is common in PACU, especially male patients [26]. Therefore, in this study, we included male patients as the study subject, and the incidence of CRBD was $65.2 \%$, which was consistent with that reported previously $[1,2,26]$. The high incidence of CRBD in male patients might be related to the anatomical characteristics, such as the long urethra and large catheter [26]. Because several urological operations need to operate on the urethra, which markedly impacts this study, and the degree of impact is different, so this study was not included in the urological patients. In the clinical practice, to deal with bladder catheter pain, we often scribble lidocaine cream at the urethral orifice, meanwhile intravenous analgesic drugs, such as fentanyl, flurbiprofen axetil could also be used, but the effect is not ideal.

In this study, we observed that intravesical dexmedetomidine instillation can significantly reduce the symptoms of postoperative CRBD according to the following underlying mechanism. Alpha 2-adrenoceptor, i.e., the $\alpha 2 \mathrm{~A}$-subtype, is expressed in the bladder, urethra, and prostate. The intra-arterial administration of an $\alpha-2$ agonist reduced the micturition pressure, bladder capacity, and micturition volume [27, 28]. dexmedetomidine is a high selective adrenergic $\alpha-2$ receptor agonist which may reduce the micturition pressure, bladder capacity, and micturition volume. There are several muscarinic receptors in bladder epithelium and efferent nerves,

\section{A}

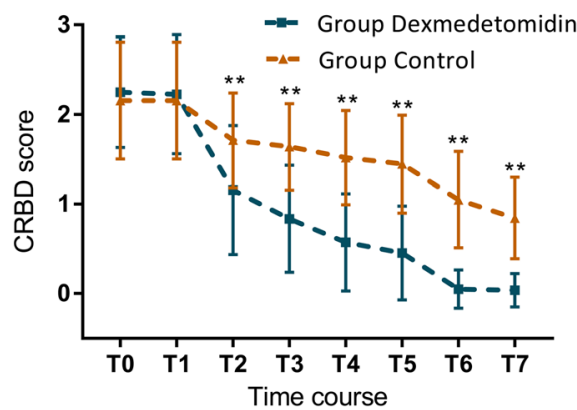

B

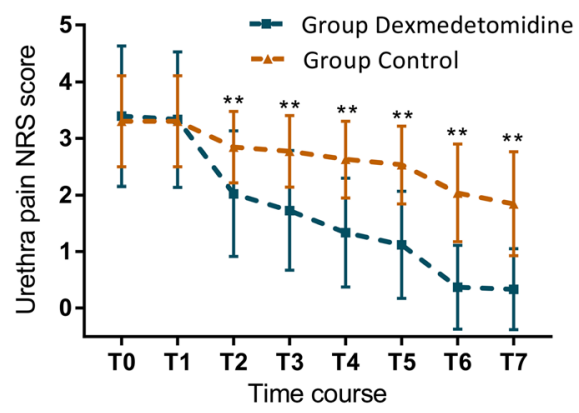

Fig. 2 Bladder stimulation scale (Fig. 2a) and urethra pain NRS score (Fig. 2b) in dexmedetomidine and control groups at various time points. CRBD, catheter-related bladder discomfort. Time course, the time point at which the patient sent to PACU (T0), intravesical instillation (T1), 30 min after intravesical instillation (T2); $1 \mathrm{~h}$ after intravesical instillation (T3), $2 \mathrm{~h}$ after intravesical instillation (T4), leaving PACU (T5), $6 \mathrm{~h}$ after operation (T6), $24 \mathrm{~h}$ after operation (T7); ** $p<0.001$ 

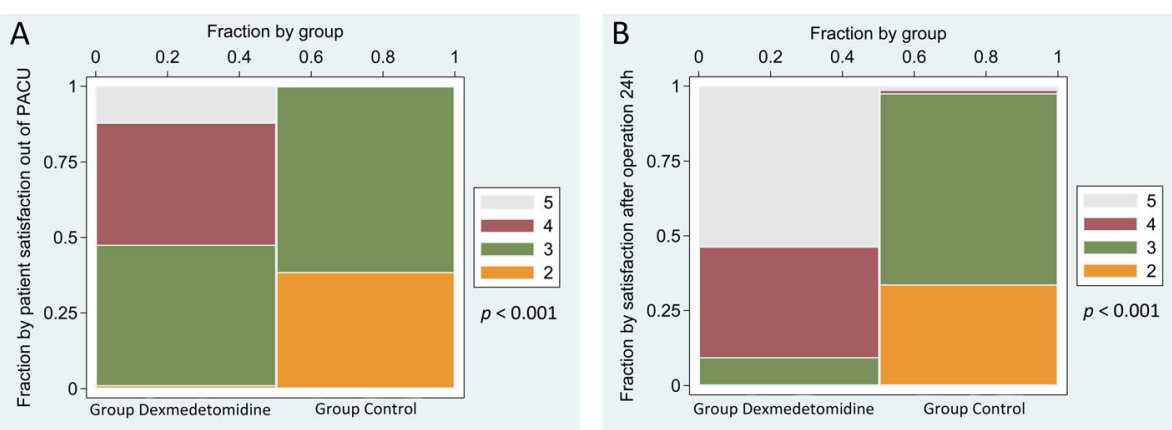

Fig. 3 Spine plot of patient satisfaction score out of PACU (Fig. 3a) and $24 \mathrm{~h}$ after the operation (Fig. 3b) in dexmedetomidine and control groups. Patient satisfaction score: 5 points, very satisfied; 4 points, satisfied; 3 points, relatively satisfied; 2 points, basically satisfied; 1 point, dissatisfied

including M2 and M3. The M3 receptor is mainly responsible for bladder contraction [29]. The catheter can stimulate the afferent nerves of the bladder to release acetylcholine, which leads to the contraction of detrusor mediated by muscarinic receptors. Therefore, muscarinic antagonists alleviate CRBD in different degrees [1]. Some studies showed that dexmedetomidine might reduce bladder contractility via $\alpha-2$ receptor and M3 muscarinic receptor antagonism [16, 17]. On the other hand, catheter stimulation can cause inflammation and increase prostaglandin secretion, which is one of the plausible reasons for CRBD [30]. Therefore, some antiinflammatory drugs can also alleviate CRBD. Another study showed that dexmedetomidine reduces the release of prostaglandins of inflammation, and hence, relieves CRBD [31]. In addition, dexmedetomidine exerts a sedative effect and relieves CRBD [10]. Another underlying mechanism is that after intravesical instillation, dexmedetomidine can be absorbed from bladder and play a systemically role of sedation, analgesia and antiinflammatory, which need to be further verified.

In the current study, dexmedetomidine plays a role in intravesical instillation. The off-label method of dexmedetomidine is often used in clinical research, which has proved to be safe and effective. For example, dexmedetomidine is safely used in subarachnoid and epidural [32], neuraxial [33] and for children intranasal [34]. As a safe and widely used drug, intravesical dexmedetomidine instillation method has been approved by the Institutional Review Board and Hospital Research Ethics Committee. Several studies [23-25] showed that intravesical instillation is an effective way of administration of drugs, which had an obvious effect on the treatment of bladderrelated diseases and reduce the systemic response. For instance, invasive immunotherapy, chemotherapy and chemohyperthermia for bladder cancer [35, 36], intragastric thermal gelatin matrix implantation for intractable hematuria [37], intragastric gentamicin for recurrent urinary tract infections treatment [38]. Dexmedetomidine is well absorbed through the mucous membrane. Iirola et al. [39] reported that peak plasma concentrations of dexmedetomidine were $38 \mathrm{~min}$ after intranasal administration, and the pharmacological effects were similar to the intravenous administration but with a later onset time. In the current study, dexmedetomidine was able to work through the bladder mucosa, with a significant effect at half an hour after administration. Even so, intravesical dexmedetomidine instillation has potential risk of bladder dysfunction such as urinary retention through a local $\alpha 2$-stimulating effect, which should be closely pay attention in clinical practice.

In this study, intravesical dexmedetomidine instillation alleviates the pain caused by catheter while in situ and on removal. The main causes of the pain during catheter in situ were as follows: the material and size of the catheter, the traction of the catheter drainage bag, the urethral discomfort, the stimulation of the bladder wall by the catheter, the obstruction of the catheter, catheter blockage, the hemorrhagic pseudopolyps, the fear of the catheter, and the psychological rejection [40]. In the present study, all patients were observed and nursed closely, and the material and size of the catheter were identical, and no catheter drainage bag traction, catheter obstruction, hemorrhagic pseudopolyps were observed. Therefore, we speculated that the main reason for the difference in the urethral pain between the two groups was the tolerance of catheter stimulation of the bladder wall and the difference in the fear and psychological rejection of the catheter. Dexmedetomidine is a solution to bladder irritation and psychological maladjustment of patients, thereby reducing the catheterinduced urethral pain. Systematic pain NRS score decreased at T4, and there was no significant change at other time points. The possible reason is that dextromethorphan was absorbed by bladder and played a systemic role, which need further study. 
Patients' satisfaction at the time point out of PACU and $24 \mathrm{~h}$ after the operation was significantly improved after intravesical dexmedetomidine instillation because there were reductions in CRBD and catheter-induced urethral pain and patient satisfaction is closely related to the postoperative outcomes [41]. The improvement in the patients' satisfaction might reduce their CRBD and urethral pain.

No complications were detected in the control and experimental groups. Since the sample size of this study is small, and the patients selected are ASA I-II, their basic conditions are well. Clinically, we will encounter CRBD to aggravate the condition of patients with coronary heart disease, and dexmedetomidine might also lead to arrhythmia and other risks. What is more, intravesical dexmedetomidine instillation perhaps could prolong bladder dysfunction through a local $\alpha 2$ stimulating effect and dexmedetomidine still reduces CRBD after $24 \mathrm{~h}$. There was no urinary retention or recatheterisation complication in dexmedetomidine group. However, only 9 ureteral catheters were removed at 6 to $12 \mathrm{~h}$ after operation, and 38 catheters were removed at 12 to $24 \mathrm{~h}$ in this study. The safety of the intravesical dexmedetomidine instillation need further clinical validation.

Nevertheless, the present study has some limitations. The number of cases is small as only 167 patients were included in this single-center study. In the future, large sample and multi-center clinical verification is essential. The patients included in this study were male patients with catheter placement under general anesthesia. The type of operation is not uniform, and the duration of operation is varied. This study did not limit the factors such as midazolam and operation time, and did not make further subgroup analysis. Further subgroup study can be carried out after expanding the sample size in the future. Prolonged follow-up for bladder dysfunction was not implemented. The safety of intravesical dexmedetomidine instillation should be further studied. It is not sure if systemic dexmedetomidine has the same effect for CRBD, further research should include an arm with intravenous dose of dexmedetomidine. All the patients included in this study were ASA I-II patients with elective surgery, and the basic condition of the patients was good. Also, critical patients have not been analyzed previously. Moreover, the effect of different doses of dexmedetomidine on CRBD was not assessed in this study. Ten milliliter normal saline was injected into the cuff balloon of catheter for all paitents to prevent slippage in our research. This may also be a potential cause of bladder wall irritation. It is regretful that we did not follow up with further research on the effect of reducing the balloon volume for reducing CRBD.

\section{Conclusions}

Dexmedetomidine $0.5 \mu \mathrm{g} / \mathrm{kg}$ intravesical instillation reduces postoperative urinary discomfort and urethra pain caused by catheter in male patients under general anesthesia and improves patient satisfaction after the operation.

\section{Abbreviations \\ CRBD: Catheter-related bladder discomfort; ASA: American Society of Anesthesiologists; NRS: Numerical rating scale; PACU: Post-anesthesia care unit; ECG: Electrocardiography; $\mathrm{SpO}_{2}$ : Peripheral oxygen saturation; NBP: Non- invasive blood pressure; RR: Respiratory rate; MAP: Mean arterial pressure; HR: Heart rate}

\section{Acknowledgements}

We thank our colleagues at the Department of Anesthesiology and Perioperative Medicine, The Second Affiliated Hospital of Anhui Medical University for their help with the samples. In addition, we thank the patients who participated in this study.

\section{Authors' contributions}

Study design: HC, BW, RL, YZ. Study conduct: HC, QL, JZ. Data analysis: HC, BW, RL, YZ. Writing paper: HC, BW, QL, JZ, RL, YZ. All authors read and approved the final manuscript.

\section{Funding}

This study was supported by the Department of Science and Technology of Anhui Province, Hefei, China (No. 201904a07020065).

\section{Availability of data and materials}

The datasets used and analyzed during this current study are available from the corresponding author on reasonable request.

\section{Ethics approval and consent to participate}

This study was approved by the Institutional Review Board and Hospital Research Ethics Committee of the Second Affiliated Hospital of Anhui Medical University [No. PJ-YX2018-004 (F2)]. Each patient provided written informed consent before participation in the study.

Consent for publication

Not applicable.

\section{Competing interests}

The authors declare that they have no competing interests.

Received: 28 June 2020 Accepted: 16 October 2020

Published online: 22 October 2020

\section{References}

1. Bai Y, Wang X, Li X, Pu C, Yuan H, Tang Y, et al. Management of CatheterRelated Bladder Discomfort in patients who underwent elective surgery. J Endourol. 2015;29(6):640-9.

2. Park JY, Hong JH, Kim DH, Yu J, Hwang JH, Kim YK. Magnesium and bladder discomfort after transurethral resection of bladder tumor: a randomized, double-blind. Placebo-controlled Study Anesthesiology. 2020. https://doi. org/10.1097/ALN.0000000000003309.

3. Binhas M, Motamed C, Hawajri N, Yiou R, Marty J. Predictors of catheterrelated bladder discomfort in the post-anaesthesia care unit. Annales francaises d'anesthesie et de reanimation. 2011;30(2):122-5.

4. Kim DH, Park JY, Yu J, Lee SA, Park S, Hwang JH, et al. Intravenous Lidocaine for the prevention of postoperative catheter-related bladder discomfort in male patients undergoing transurethral resection of bladder tumors: a randomized, double-blind, controlled trial. Anesth Analg. 2019. https://doi. org/10.1213/ANE.0000000000004405.

5. Agarwal A, Dhiraaj S, Singhal V, Kapoor R, Tandon M. Comparison of efficacy of oxybutynin and tolterodine for prevention of catheter related bladder discomfort: a prospective, randomized, placebo-controlled, double-blind study. Br J Anaesth. 2006;96(3):377-80. 
6. Kim HC, Park HP, Lee J, Jeong MH, Lee KH. Sevoflurane vs. propofol in postoperative catheter-related bladder discomfort: a prospective randomized study. Acta Anaesthesiol Scand. 2017;61(7):773-80.

7. Li S, Song L, Ma Y, Lin X. Tramadol for the treatment of catheter-related bladder discomfort: a randomized controlled trial. BMC Anesthesiol. 2018; 18(1):194.

8. Maghsoudi R, Farhadi-Niaki S, Etemadian M, Kashi AH, Shadpour P, Shirani A, et al. Comparing the efficacy of Tolterodine and gabapentin versus placebo in catheter related bladder discomfort after percutaneous Nephrolithotomy: a randomized clinical trial. J Endourol. 2018;32(2):168-74.

9. Shin YS, Doo AR. Managing postoperative catheter-related bladder discomfort. J Anesth. 2019;33(2):347.

10. Kim JA, Ahn HJ, Yang M, Lee SH, Jeong H, Seong BG. Intraoperative use of dexmedetomidine for the prevention of emergence agitation and postoperative delirium in thoracic surgery: a randomized-controlled trial. Can J Anaesth. 2019;66(4):371-9.

11. Lee $\mathrm{C}$, Lee $\mathrm{CH}$, Lee $\mathrm{G}$, Lee $\mathrm{M}$, Hwang J. The effect of the timing and dose of dexmedetomidine on postoperative delirium in elderly patients after laparoscopic major non-cardiac surgery: a double blind randomized controlled study. J Clin Anesth. 2018;47:27-32.

12. Shin HJ, Koo BW, Bang SU, Kim JH, Hwang JW, Do SH, et al. Intraoperative dexmedetomidine sedation reduces the postoperative agitated behavior in elderly patients undergoing orthopedic surgery compared to the propofol sedation. Minerva Anestesiol. 2017;83(10):1042-50.

13. Su X, Meng ZT, Wu XH, Cui F, Li HL, Wang DX, et al. Dexmedetomidine for prevention of delirium in elderly patients after non-cardiac surgery: a randomised, double-blind, placebo-controlled trial. Lancet. 2016;388(10054): 1893-902.

14. Subramaniam B, Shankar P, Shaefi S, Mueller A, O'Gara B, Banner-Goodspeed $V$, et al. Effect of intravenous acetaminophen vs placebo combined with Propofol or Dexmedetomidine on postoperative delirium among older patients following cardiac surgery: the DEXACET randomized clinical trial. Jama. 2019:321(7):686-96

15. Hegde SS. Muscarinic receptors in the bladder: from basic research to therapeutics. Br J Pharmacol. 2006;147(Suppl 2):S80-7.

16. Singh TK, Sahu S, Agarwal A, Gupta D, Mishra P. Dexmedetomidine for prevention of early postoperative catheter-related bladder discomfort in voluntary kidney donors: prospective, randomized, double-blind, placebocontrolled trial. J Anaesthesiol Clin Pharmacol. 2018;34(2):211-5.

17. Takizuka A, Minami K, Uezono Y, Horishita T, Yokoyama T, Shiraishi M, et al. Dexmedetomidine inhibits muscarinic type 3 receptors expressed in Xenopus oocytes and muscarine-induced intracellular Ca2+ elevation in cultured rat dorsal root ganglia cells. Naunyn Schmiedeberg's Arch Pharmacol. 2007;375(5):293-301.

18. Akca B, Aydogan-Eren E, Canbay O, Karagoz AH, Uzumcugil F, Ankay-Yilbas $A$, et al. Comparison of efficacy of prophylactic ketamine and dexmedetomidine on postoperative bladder catheter-related discomfort. Saudi Med J. 2016;37(1):55-9.

19. Kim HC, Lee YH, Jeon YT, Hwang JW, Lim YJ, Park JE, et al. The effect of intraoperative dexmedetomidine on postoperative catheter-related bladder discomfort in patients undergoing transurethral bladder tumour resection: a double-blind randomised study. Eur J Anaesthesiol. 2015;32(9):596-601.

20. Kwon Y, Jang JS, Hwang SM, Lee JJ, Tark H. Intraoperative administration of dexmedetomidine reduced the postoperative catheter-related bladder discomfort and pain in patients undergoing lumbar microdiscectomy. J Anesth. 2018;32(1):41-7.

21. Liu K, Chen J, Zhang K, Wang S, Li X. A diagnostic prediction model of acute symptomatic portal vein thrombosis. Ann Vasc Surg. 2019;61:394-9.

22. Wu M, Liang Y, Dai Z, Wang S. Perioperative dexmedetomidine reduces delirium after cardiac surgery: a meta-analysis of randomized controlled trials. J Clin Anesth. 2018;50:33-42.

23. Krhut J, Navratilova M, Sykora R, Jurakova M, Gartner M, Mika D, et al. Intravesical instillation of onabotulinum toxin a embedded in inert hydrogel in the treatment of idiopathic overactive bladder: a double-blind randomized pilot study. Scand J Urol. 2016;50(3):200-5.

24. Marttila $T$, Jarvinen $R$, Liukkonen $T$, Rintala E, Bostrom $P$, Seppanen $M$, et al. Intravesical Bacillus Calmette-Guerin versus combination of Epirubicin and interferon-alpha2a in reducing recurrence of non-muscle-invasive bladder carcinoma: FinnBladder-6 study. Eur Urol. 2016;70(2):341-7.

25. Tyagi $P$, Kashyap $M$, Hensley $H$, Yoshimura N. Advances in intravesical therapy for urinary tract disorders. Expert Opin Drug Deliv. 2016;13(1):71-84.
26. Ryu JH, Hwang JW, Lee JW, Seo JH, Park HP, Oh AY, et al. Efficacy of butylscopolamine for the treatment of catheter-related bladder discomfort: a prospective, randomized, placebo-controlled, double-blind study. $\mathrm{Br}$ J Anaesth. 2013;111(6):932-7.

27. Ishizuka O, Mattiasson A, Andersson KE. Role of spinal and peripheral alpha 2 adrenoceptors in micturition in normal conscious rats. J Urol. 1996;156(5): 1853-7.

28. Michel MC, Vrydag W. Alpha1-, alpha2- and beta-adrenoceptors in the urinary bladder, urethra and prostate. Br J Pharmacol. 2006;147(Suppl 2): S88-119.

29. Yamanishi T, Chapple CR, Chess-Williams R. Which muscarinic receptor is important in the bladder? World J Urol. 2001;19(5):299-306.

30. Andersson KE. Detrusor myocyte activity and afferent signaling. Neurourol Urodyn. 2010;29(1):97-106

31. Liu Y, Liu W, Wang X, Wan Z, Liu Y, Leng Y. Dexmedetomidine relieves acute inflammatory visceral pain in rats through the ERK pathway, toll-like receptor signaling, and TRPV1 channel. J Mol Neurosci. 2018;66(2):279-90.

32. Li YZ, Jiang Y, Lin H, Yang XP. Subarachnoid and epidural dexmedetomidine for the prevention of post-anesthetic shivering: a meta-analysis and systematic review. Drug Design Dev Therapy. 2019;13:3785-98.

33. Abdallah FW, Brull R. Facilitatory effects of perineural dexmedetomidine on neuraxial and peripheral nerve block: a systematic review and meta-analysis. Br J Anaesth. 2013;110(6):915-25

34. Ghai B, Jain K, Saxena AK, Bhatia N, Sodhi KS. Comparison of oral midazolam with intranasal dexmedetomidine premedication for children undergoing CT imaging: a randomized, double-blind, and controlled study. Paediatr Anaesth. 2017;27(1):37-44.

35. Biot C, Rentsch CA, Gsponer JR, Birkhauser FD, Jusforgues-Saklani H, Lemaitre F, et al. Preexisting BCG-specific T cells improve intravesical immunotherapy for bladder cancer. Sci Transl Med. 2012;4(137):137ra172.

36. Campodonico F, Di Stasi S, Lev GM, Terrone C, Bongiovanni L, Mattioli F, et al. Intravesical chemotherapy and Chemohyperthermia in non-muscleinvasive bladder Cancer; an overview on drug administration technologies and pharmacokinetics. Curr Drug Metab. 2017;18(7):657-65.

37. Margreiter M, Sharma V, Schauer I, Klingler HC. Intravesical hemostatic gelatin matrix instillation in the management of intractable hematuria. Urology. 2013:82(3):724-8

38. Stalenhoef JE, van Nieuwkoop C, Menken PH, Bernards ST, Elzevier HW, van Dissel JT. Intravesical gentamicin treatment for recurrent urinary tract infections caused by multidrug resistant bacteria. J Urol. 2019;201(3):549-55.

39. lirola T, Vilo S, Manner T, Aantaa R, Lahtinen M, Scheinin M, et al. Bioavailability of dexmedetomidine after intranasal administration. Eur J Clin Pharmacol. 2011;67(8):825-31.

40. Wilson M. Causes and management of indwelling urinary catheter-related pain. Br J Nurs. 2008;17(4):232-9.

41. Tevis SE, Kennedy GD, Kent KC. Is there a relationship between patient satisfaction and favorable surgical outcomes? Adv Surg. 2015;49:221-33.

\section{Publisher's Note}

Springer Nature remains neutral with regard to jurisdictional claims in published maps and institutional affiliations.

Ready to submit your research? Choose BMC and benefit from:

- fast, convenient online submission

- thorough peer review by experienced researchers in your field

- rapid publication on acceptance

- support for research data, including large and complex data types

- gold Open Access which fosters wider collaboration and increased citations

- maximum visibility for your research: over $100 \mathrm{M}$ website views per year

At $\mathrm{BMC}$, research is always in progress.

Learn more biomedcentral.com/submission 